with water; but fortunately the instruments all escaped unhurt, and nothing was lost but a pair of boots and a couple of hats, and all our salt and most of our sugar, which the water dissolved.

For the next two days we were employed repairing the boat, it blowing a gale and raining hard the whole time, so that we could dry nothing; and when at last we started, almost constant head-winds and frequent gales made our journey a slow one. Fortunately our course lay among islands, so that we enjoyed a certain degree of shelter from the wind, and harbours of refuge were always at hand in case of necessity. These islands are all of rock and well wooded, but destitute at this season of the year of game, which was unfortunate for us, as our provisions were getting short, and our crew were reduced to a pound of flour per diem, with a little tea and sugar. There were not even fish to be caught, though they are usually abundant, but I suppose the rough weather had driven them into the deep water. At last we shot some seagulls, and we were all glad enough to eat them.

At length, on the 30 th, we reached Fort Rie, which lies in lat. $62^{\circ} 38^{\prime}$ N. an 1 long. I $15^{\circ} 25^{\prime}$ W., half way up a long gulf that run; for about Ios miles in a north-west direction from the mouth of the Yellow Knife River. The fort is situated at the foot of a rocky hill that rises some 200 feet above the lake, which is about four miles wide at this point. The Indians who resort here for trade hunt for the most part in the "barren lands" near the Coppermine River, whence they bring quantities of skins and beef from the musk-ox, which seems to be very abundant. Deer too are very plentiful, and in the winter they migrate in great herds from the barren lands to the country between the arm of the lake on which Fort Rae lies and the Mackenzie. Sometimes these herds pass quite close to the fort, and take two or three days in passing. Their numbers must be very great; a single band has bəen known to kill over 15,000 in an ordinary season.

This year the deer have prssed at som e distance, but the In tians are now bringing in fresh meat daily.

These Indians are of the "Dog-rib" tribe-T'akfwelottine, they call themselves-a quiet, inoffensive race, like all the wood-Indians. They are almost all Roman Catholics, the missionaries of that religion being very nu nerous in the country, and they are certainly very devoted and hard-working. There are also Protestant missionaries, but they do not appear to have made any converts.

The Dor-ribs are a branch of the Chipewyan family which occupies all that portion of the continent between the Rocky Mountains and Hudson's Bay to the north of the parallel of $55^{\circ}$. They are unprepossessing in appearance, and their language is almost unpronounceable by a European. Their alphabet, if they had one, would contain no less than seventy-one letters, that being the number of distinct sounds. I believe the language is allied to the ancient Mexican-at any rate the Navajo is the nearest to it of existing languages-and the combinations of letters that one sees in Mexican names ( $t l$, for instance) are common in this language. The Dog-ribs have the remarkable peculiarity of a national habit of stammering, which is most marked in those who seldom come in to the fort. They treat their women with more kindness than is usual among the American Indians.

Fort Rae is one of the windiest and cloudiest places $I$ have ever seen, but I am told this is an exceptional year. It is certainly a very late autumn ; the lake was not frozen till November 1, and it is only within the last day or two that the cold weather has really set in. Last night the thermometer was at $-34^{\circ}$.

My space is at an end, but by the next mail I hope to give you an account of our winter here.

Fort Rae, December I
ON THE NATURE OF INHIBITION, AND THE ACTION OF DRUGS UPON IT ${ }^{1}$

IV.

$A$ CONDITION very nearly similar to that caused by atropia is produced by morphia. When this substance is given to a frog, its effects are exactly similar to those produced by the successive removal of the different parts of the nervous system from above downwards. Goltz has shown that when the cerebral lobes are removed from the frog it loses the power of voluntary motion and sits still ; when the optic lobes are removed it will spring when stimulated, but loses the power of directing its movements. When the cerebellum is removed it loses the power of springing at all; and when the spinal cord is destroyed reflex action is abolished.

Now these are exactly the effects produced by morphia, the frog poisoned by it first losing voluntary motion, next the power of directing its movements, next the power of springing at all, and lastly reflex action. But after reflex astion is destroyed by morphia and the frog is apparently dead, a very remarkable condition appears, the general flaccidity passes away and is succeeded by a stage of excitement, a slight touch causing violent convulsions just as if the animal had been poisoned by strychnia. ${ }^{2}$

The action of morphia here appears to be clearly that of destroying the function of the nerve centres from above downwards, causing paralysis first of the cerebral lobes, next of the optic lobes, next of the cerebellum, and next of the cord. But it seems probable that the paralysis of the cord first observed is only apparent and not real, and in order to explain it on the ordinary hypothesis we must assume that during it the inhibitory centres in the cord are intensely excite 1 so as to prevent any motor action, that afterwards they become completely paralysed, and thus we get convulsions ozcurring from slight stimuli.

On the hypothesis of interference, the phenomena produced both by atropia and by morphia can be more simply explained. These drugs, acting on the nervous structures, gradually lessen the functional activity both of cells and of fibres; the impulses are retarded, and thus the length of nervous connection between the cells of the spinal cord, which is calculated to keep them in proper relation in the normal animal, just suffices at a certain stage to throw the impulses half a wave-length behind the other, and thus to cause complete inbibition and apparent paralysis.

As the action of the drug goes on, the retardation becomes still greater, and then the impulses are thrown very nearly, but not quite, a whole wave-length behind the other, and thus they coincide for a short time, but gradually again interfere, and therefore we get on the application of a stimulus, a tonic convulsion followed by several clonic ones, and then by a period of rest. This explanation is further borne out by the fact observed by Fraser, that the convulsions caused by atropia occurred more readily during winter, when the temperature of the laboratory is low and the cold would tend to aid the action of the druy in retarding the transmission of impulses. ${ }^{3}$

The effect of strychnia in causing tetanus is very remarkable; a very small dose of it administered to a frog first renders the animal most sensitive to reflex impulses, so that slight impressions which would normally have no effect, produce reflex action. As the poisoning proceeds, a slight stimulus no longer produces a reflex action limited to a few muscles, but causes a general convulsion throughout all the body, all muscles being apparently put equally on the stretch. In man the form assumed by the body is that of a bow, the head and the heels being bent backwards, the hands clenched, and the arms tightly drawn to the body.

2 Marshall Hall, Menoirs on the Nerv sus System, p. vii. (London, 1837) Witkowski. Archiv für exper Path. unf Pharm., Band vii. p. 247 ${ }_{3}$ Transacti ns of the Royal Syciety of Edinburgh, vol. xxv. p. 467. 
My friend Dr. Ferrier has shown that this position is due to the different strengths of the various muscles in the body. All being contracted to their utmost, the stronger overpower the weaker, and thus the powerful extensors of the back, and muscles of the thighs keep the body arched backwards and the legs rigid, while the adductors and flexors of the arms and fingers clench the fist and bend the arms, and draw them close to the body. ${ }^{1}$ The convulsions are not continuous, but are clonic ; a violent convulsion coming on and lasting for a while, and then being succeeded by an interval of rest, to which after a little while another convulsion succeeds. The animal generally dies either of asphyxia during a convulsion, or of stoppage of the heart during the interval.

When the animal is left to itself the convulsions-at least in frogs-appear to me to follow a certain rhythm, the intervals remaining for some little time of nearly the same extent.

A slight external stimulus, however, applied during the interval - or at least during a certain part of it-will bring on the convulsion. But this is not the case during the whole interval. Immediately after each convulsion has ceased I have observed a period in which stimulation applied to the surface appears to have no effect whatever.

It is rather extraordinary also, that although touching the surface produces convulsions, irritation of the skin by acid does not do so. ${ }^{2}$.

The cause of those convulsions was located in the spinal cord by Magendie in an elaborate series of experiments.

Other observers have tried to discover whether any change in the peripheral nerves also took part in causing convulsion; but from further experiments it appears that the irritability of the sensory nerves is not increased. ${ }^{3}$

According to Rosentbal, strychnia does not affect the rate at which impulses are transmitted in peripheral nerves; according to him, however, it lessens the time required for reflex actions. Wundt came to the conclusion that the refiex time was on the contrary increased.

In trying to explain the phenomenon of strychnia tetanus on the hypothesis of interference, one would have been inclined by Rosenthal's experiments to say that strychnia quickened the transmission of impulses along those fibres in the spinal cord which connect the different cells together.

The impulses which normally, by travelling further round fell behind the simple motor ones by half a wavelength, and thus inhibited them, would now fall only a small fraction of a wave-length behind, and we should have stimulation instead of inhibition.

Wundt's results, on the other hand, would lead to the same result by supposing that the inhibitory wave was retarded so as to fall a whole wave-length behind the motor one. On the assumption, however, that the fibres which pass transversely across from sensory to motor cells, and those that pass upwards and downwards in the cord connecting the cells of successive strata in it, are equally affected, we do not get a satisfactory explanation of the rhythmical nature of the convulsions. By supposing, however, that these are not equally affected, but that the resistance in onc-let us say, that in the longitudinal fibres-is more increased than in the transverse fibres we shall get the impulses at one time thrown completely upon each other causing intense convulsion, at another half a wave-length behind, causing complete relaxation, which is exactly what we find.

This view is to some extent borne out by the different effect produced by a constant current upon these convulsions, according as it is passed transversely or longitudinally through the spinal cord. Ranke found that when passed transversely, it has no effect, but when

I Brain, vol. iv. p. $3{ }^{13}$

2 Eckhard, Hermann's Handb. d. Physiol. Band ii. Th. 2, p. 43. 3 Bernstein quoted by Eckhard, op. cit. p. 40 . Walton, Ludwigs
rbeiten, 1882. passed longitudinally in either direction, it completely arrests the strychnia convulsions, and also the normal reflexes which are produced by tactile stimuli.

Ranke's observations have been repeated by others with varying result, and this variation may, I think, be explained by the effect of temperature.

Near the beginning of this paper I mentioned that the touchstone of the truth or falsehood of the hypothesis of inhibition by interference was to be found in the results of quickening or slowing the rate of transmission of stimuli.

Heat and cold are the two agents regarding whose action in this respect we have the most trustworthy experimental data. In peripheral nerves, heat up to a certain point quickens the transmission of stimuli, and cold retards it. In the spinal cord warmth increases the excitability, and at a temperature of 29 to 30 may of itself cause tetanus. ${ }^{1}$ Cold also beyond a certain temperature increases the reflex excitability.

The effect of warmth and cold upon stry chnia tetanus is what we would expect on the hypothesis of interference. With small doses of strychnia warmth abolishes the convulsions, while cold increases them. When large doses are given, on the contrary, warmth increases the convulsions, and cold abolishes them. ${ }^{2}$

We may explain this result on the hypothesis of interference in the following manner:-

If a small dose of strychnia retard the transmission of nervous impulses so that the inhibitory wave is allowed to fall rather more than half a wave-lengtb, but not a whole wave-length, behind the stimulant wave, we should have a certain amount of stimulation instead of inhibition. Slight warmth, by quickening the transmission of impulses, should counteract this effect, and should remove the effect of the strychnia. Cold, on the other hand, by causing still further retardation, should increase the effect. With a large dose of strychnia, the transmission of the inhibitory wave being still further retarded, the warmth would be sufficient to make the two waves coincide, while the cold would throw back the inhibitory wave a whole wave-length, and thus again abolish the convulsions.

The effect of temperature on the poisonous action of guanidine is also very extraordinary, and is very hard to explain by the ordinary hypotheses, although the phenomena seem quite natural when we look at them as cases of interference due to alterations in the rapidity with which the stimuli are transmitted along nervous structures. Guanidine produces, in frogs poisoned by it, fibrillary twitchings of the muscles, which are well marked at medium temperatures, but are abolished by extremes of heat and cold. Thus Luchsinger has found that, when four frogs are poisoned by this substance, and one is placed in ice-water, another in water at $18^{\circ} \mathrm{C}$., a third in water at $25^{\circ} \mathrm{C}$., and a fourth in water at $32^{\circ} \mathrm{C}$., the fibrillary twitchings soon disappear from the frog at $\mathrm{O}^{\circ} \mathrm{C}$, and only return when its temperature is raised to about $18^{\circ} \mathrm{C}$. In the frog at $18^{\circ} \mathrm{C}$. convulsions occur, which are still greater in the one at $25^{\circ} \mathrm{C}$. In the frog at $32^{\circ} \mathrm{C}$, , on the other hand, no trace of convulsions is to be seen; the animal appears perfectly well, and five times the dose of the poison, which at ordinary temperatures would convulse it, may be given to it without doing it any harm, so long as it remains in the warmtb, ${ }^{3}$ although when it is cooled down the effect of the poison at once appears.

Another cause of tetanus that is difficult to understand on the ordinary hypothesis of inhibitory centres is the similar effect of absence of oxygen and excess of oxygen. When an animal is confined in a closed chamber, without oxygen it dies of convulsions; when oxygen is gradually ${ }^{I}$ Cayrade, Recherches critiques et exper. sur les Mouvements Reflexes,
p. ${ }_{2} 4$. 2 Kunde and Virchow quoted by Eckhard, op. cit. p. 44 ; Foster, Journal of Anatomy and Physiology, November 1873, p. 45 .

3 Luchsinger, Physiclogische Studien, Leipzig, 1882, p. 44. 
introduced before the convulsions become too marked, it recovers. But when the pressure of oxygen is gradually raised above the normal, the animal again dies of convulsions. This is evidently not the effect of mere increase in atmospheric pressure, but the effect of the oxygen on the animal, inasmuch as 25 atmospheres of com non air are required to produce the oxygen convulsions, while 3 atmospheres of pure oxygen are sufficient. This effect is readily explained on the hypothesis of interference by supposing that the absence of oxygen retards the transmission of impulse; in the nerve-centres; so that we get those which ou ght ordinarily to inhibit one another, coinciding and causing convulsions. Increased supply of oxygen gradually quickens the transmission of impulses until the waves first reach the normal relation, and then the normal rate being exceeded, the impulses once more nearly coincide, and convulsions are produced a second time.

In discussing the action of the nervous system we have hitherto taken into azcount only that of the nerve fibrils, and left out of the question the nerve cells. We have assumed that the waves arrived in the reservoir (in our diagram) from a distance, and were simply transmitted along channels, but in the nervous system we have to take into account the origination of the waves in the nerve cells themselves, as well as their propagation along the nerve channels.

There is a great difference between the function of the nerve cell and of the nerve fibre analogous to that which exists between the cell and the wire in a galvanic battery. The particular form of energy which we met with in both cases originates in the cell and is transmitted along the fibre or the wire. In both cases also the energy appears to originate from chemical changes going on in the cell. Material waste of some sort goes on in both, and in both the products of this waste if allowed to accu nulate will by and by arrest the action.

We find an indication of the difference between the amount of chemical change which goes on in the nerve cell and in the nerve fibre in the amount of blood sup. plied to each respectively. The nerve cells are abundantly supplied with blood, and tha nerve fibres very sparingly so. The free supply of blood secures to the nerve cells both the supply of fresh material and ready removal of waste products.

Perhaps the best illustration that we can find in physics of the processes which take place in the nervous and muscular systems is however afforded by singing flame; in which the sound; and movements are produced by very numerous small explosions : for both in the nervous and muscular systems the tissue change appears to go on as a series of small explosions. The material which yields nervous and muscular energy undergoes oxidation, but the oxygen concerned in the process is not derived directly from the external air. Substances which yield oxygen are contained within the tissues themselves just as nitre is contained along with oxidisable substances in a charge of gunpowder.

In this paper also we have spoken of waves of nervous interference as if they were simple, but it is much more probable that they are very complex, resembling much more the beats of sound produced by two singing flames which are not in unison, than simple waves of water.

The number of nervous discharges which issue from the motor cells of the spinal cord during tetanus and set the muscles in action is, according to Dr. Burdon Sanderson, about 16 per second, but in all probability each of these impulses consists of a large number of small vibrations. In rhythmical actions, such as that of the respiration, we have probably at the very least three rhythms, Ist, exceedingly rapid vibrations in the nervous cells; 2nd, slower vibrations or beats from 16 or 18 per second, which issue from them and excite the muscles to action; and 3 rd, a still slower rhythm, of 16 per minute, probably due to interference between groups of cells, which leads to inspiratory movements alternating with rest or with active exspiration. The consideration of these complicated phenomena would, however, at present lead us tos far, and they as well as the subject of nervous interference in the heart and rhythmic contraction of muscles, must be reserved for another time.

In this paper I must be content with the attempt to show that inhibition and stimulation in the nervous system are not dependent on special inhibitory or stimulating centres, but are merely relative conditions depending on the length of path along which the stimulus has to travel and the rate of its transmission. The test of the truth or falsehood of this hypothesis is to be found in the effect of alteration in the rapidity of nervous transmission upon inhibitory phenomena. The application of this test appears, so far as our present data go, to support this hypothesis.

T. LAUDER BRUNTON

\section{BEN NEVIS OBSERVATORY}

I N NATURE, vol. xxvii. p. 39, I gave a brief notice that on November I-owing to stress of weather forbidding the regular daily ascents of Ben Nevis - I was obliged to discontinue the daily work of the meteorological observing system on the summit and slopes of the mountain. This was in simultaneous connection with my system of observations near the sea-level at Arhintore, Fort William. As in the previous summer, I had the honour to organise and carry on the work under the auspices of the Scottish Meteorological Society. The experience gained in $188 \mathrm{r}$, when I first commenced observins on the Ben, enabled me to draw up and submit to the Society a more elaborate plan of mountain observation for the summer and autumn of 1882 ; and as I have been fortunate enough to carry it through for five months without any hitch, and as I am not aware that anything of the kind had, previous to my first undertaking, been attempted, I am naturally anxious that NATURE should have a more complete account of my last year's operations. My plan was to have fixed stations at different altitudes between the main observatories at the base and on the summit of the mountain so plazed in fact that I could observe regularly at halfhourly intervals during the daily ascent and descent of the Ben; to extend the number of summit observations to five sets; and to have in every case simultaneous observations taken at the sea-level station-my grand base of operations. All this was with a view to localising disturbances existing in the stratum of atmosphere between the sea-level and the top of Ben Nevis, to furthering meteorological research generally, and so ultimately to gain forecasting material. I arrived at Fort William from Edinburgh on May 25, and at once proceeded to give effect to my plans. During the next few days I was engaged mainly in erecting Stevenson's thermometer screens, and laying out the sea-level station; in establishing a new "midway" observatory at the lake, erecting screen, and building there a granite cairn for a barometer and in reopening the temporary observatory on the summit of the mountain. It was only by dint of great exertion and a gang of men that I got all in order on the top of the Ben on May 3I. I had no occasion, however, to alter the arrangements of the previous summer; and the heavy work of reopening chiefly consisted in digging out from the vast accumulations of snow the barometer cairn, hut, and thermometer cage which here, as a safeguard, incloses Stevenson's screen. The snow, in fact, was nearly four feet deep, and it was necessary to cut out wide areas around the instruments. I also erected another screen to contain Negretti and Zambra's self-registering clock-hygrometer, most kindly placed at my disposal by that eminent firm for the purpose of obtaining 9 p.m. values. I had also to fix a new roof of ship's canvas to the rude shanty that affords some little 